\title{
High 'Loss to Follow-Up’ of Adolescent Pregnancies in Yaounde. What are the Determinants and Challenges?
}

\author{
Juluis Sama Dohbit ${ }^{1,2 *}$, Esther Ngo Um Meka', ${ }^{1,2}$ Mve $\mathrm{KV}^{2}$, Bogne JB${ }^{1}$, Pascal Foumane ${ }^{1,2}$, Bolo ${ }^{1}$, Hugette NR \\ Zambo $^{1}$, Banmi NL ${ }^{1}$, Joel Noutakdie Tochie ${ }^{3}$, Bella H Assumpta ${ }^{1}$ and Angwafo Fru ${ }^{1,3}$ \\ ${ }^{1}$ Yaounde Gynaeco-Obstetrics and Paediatric Hospital, Cameroun \\ ${ }^{2}$ Departement of Gynaecology and Obstetrics, University of Yaoundé, Cameroon
}

${ }^{3}$ Departement of Surgery and Specialities, University of Yaoundé, Cameroon

Submission: October 11, 2018 ; Published: October 31, 2018

*Corresponding author: Juluis Sama Dohbit, Yaounde Gynaeco-Obstetrics and Paediatric Hospital, Cameroun

Abstract

Background: Adolescent pregnancies are characterized by high rate of maternal, foetal and neonatal morbi-mortality. Adherence to antenatal care still remains a major challenge amongst pregnant adolescents in a resource-limited setting.

Objective: The aim of this study was to determine the rate of loss to follow up of adolescent pregnancies and describe the determinants of this loss to follow up.

Methods: We conducted a 1: 1.3 unmatched case-control study at adolescent clinic of the Yaounde Gynaeco-Obstetrics and Paediatric Hospital, Cameroun from November 2016 to June 2017. Cases were pregnant adolescents aged between 14 to 19 years loss to follow-up during antenatal care, meanwhile those who completed their pregnancy follow-up constituted the controls. An error margin of $5 \%$ was set. A multivariate analysis was performed to rule out confounders.

Results: A total of 549 adolescents consulted for antenatal care in the adolescent clinic. Overall, 308 (56.1\%) of them completed their follow-up till delivery given a rate of loss to follow up of 44\%. After multivariate analysis independent risk factors associated with loss to follow-up were working in the informal sector, originating from the North-West region of Cameroon, the long waiting period during antenatal consultation, long distance to the hospital, medical fees (antenatal consultations and laboratory) considered as expensive, high cost of delivery, the aggressive attitude of the hospital staff, large family size and low socioeconomic status.

Conclusion: About half of all adolescents' pregnancies in Yaoundé have a loss to follow up. This high rate of loss to follow up is due to multiple sociodemographic, cultural, medical, logistics and obstetric determinants. The identification of these factors could help decision makers in improving adolescent access to quality medical care during pregnancy.

Keywords: Adolescents; Teenage; Pregnancy; Loss to follow up; Determinants

\section{Introduction}

Adolescent pregnancy is a public health problem. Globally, it's constitute about 49 deliveries per 1000 deliveries making $11 \%$ of all deliveries [1]. The huge majority of these deliveries occur in the low-and middle-income countries and particularly in Sub-Saharan Africa where more than half of the female population deliver before the age of $20[1,2]$. In Cameroon, Tebeu et al. find out that adolescent deliveries make up about $14.2 \%$ of all deliveries [3].

Pregnancy in adolescents should attract a particular attention due to increase morbidity mortality for the mother and the future baby. These complications may include: hypertensive disorders, anemia, dystocia, preterm delivery, as well as maternal and child deaths [2]. Maternal death is doubled in adolescents when compared with women aged 20 to 24 years, making it the second leading cause of death in girls aged 15 to 19 years [1]. Babies born of these adolescents are more exposed to risk of morbidity and mortality when compared to those of older women, and it is most often related to prematurity and small for gestational age birth weights. One of the principal determinants in this age group is the low access to health care, school dropout and low social status $[2,4]$.

In an effort to resolve this problem in the Yaounde GynaecoObstetric and Pediatric Hospital (HGOPY) in Cameroon, the administration of the hospital created an Adolescent Clinic with the objective of taking care of their health concerns through mass education, health campaigns, open-door activities and free clinical consultation. This study was carried out in the Adolescent Clinic of HGOPY. The objective was to describe the general 
characteristics of adolescents followed up with pregnancy in this clinic, determine the rate of loss to follow up and describe the sociodemographic, medical, and obstetric determinants of these loss to follow up adolescents pregnancies. Our preliminary literature search did not find a similar study done before in Cameroon. A few incomplete studies were found in the African literature, which grouped the factors into individual factors, family and obstetrical factors [4-7].

\section{Materials and Methods}

\section{Study design and setting}

An unmatched case-control study was carried out in the adolescent clinic of HGOPY to determine the factors associated with loss to follow-up during antenatal care in adolescent pregnancies for seven months, from November 2016 to June 2017. The group of cases was the loss to follow-up, meanwhile those who completed their pregnancy follow-up constituted the control group. The Schlesselman's formula was used to calculate the minimum sample size required, estimated at 210 participants at a ratio of 1 : 1.3 cases and controls respectively. Ethical clearance was obtained from the Institutional Review Board of the Faculty of Medicine and Biomedical Sciences of the University of Yaounde I, and also from the Institutional Ethics Result

\section{General characteristics of the study population}

Table 1: Sociodemographic characteristics of the Adolescents.

\begin{tabular}{|c|c|c|c|c|}
\hline Variables & Case & Control & OR $(95 \% \mathrm{CI})$ & P-value \\
\hline & $\mathrm{n}=97$ & $n=127$ & & \\
\hline & $\mathrm{n}(\%)$ & $\mathrm{n}(\%)$ & & \\
\hline \multicolumn{5}{|c|}{ Age (years) } \\
\hline [14-17] & $13(13.4)$ & $18(14.2)$ & $0.94(0.43-2.03)$ & 0.510 \\
\hline [17-20] & $84(86.6)$ & 109 (85.8) & $1.07(0.49-2.35)$ & 0.510 \\
\hline \multicolumn{5}{|c|}{ Profession } \\
\hline Pupil & $58(59.8)$ & $81(63.8)$ & $0.84(0.49-1.46)$ & 0.320 \\
\hline Student & $12(12.4)$ & $17(13.4)$ & $0.91(0.4-2.02)$ & 0.490 \\
\hline Housewife & $10(10.3)$ & $24(18.9)$ & $0.49(0.22-1.08)$ & 0.050 \\
\hline Jobless & $4(4.1)$ & $2(1.6)$ & $2.69(0.47-21.27)$ & 0.220 \\
\hline Informal sector & $11(11.3)$ & $3(2.4)$ & $5.29(1.43-19.51)$ & 0.007 \\
\hline Fonctionnaire & $2(2.1)$ & $0(0)$ & & 0.190 \\
\hline \multicolumn{5}{|c|}{ Region of Origin } \\
\hline Centre & $34(35.1)$ & $33(26)$ & $1.54(0.86-2.74)$ & 0.090 \\
\hline South & $4(4.1)$ & $10(7.9)$ & $0.5(0.13-1.62)$ & 0.190 \\
\hline Littoral & $5(5.2)$ & $10(7.9)$ & $0.64(0.19-1.92)$ & 0.300 \\
\hline East & $2(2.1)$ & $0(0)$ & & 0.190 \\
\hline Adamawa & $2(2.1)$ & $0(0)$ & & 0.190 \\
\hline North & $3(3.1)$ & $6(4.7)$ & $0.64(0.13-2.66)$ & 0.400 \\
\hline North-West & $9(9.3)$ & $1(0.8)$ & $12.89(2.04-286.86)$ & $<0.001$ \\
\hline Extreme-North & $1(1)$ & $5(3.9)$ & $0.25(0.01-1.88)$ & 0.180 \\
\hline West & 37 (38.1) & $61(48)$ & $0.67(0.39-1.14)$ & 0.090 \\
\hline
\end{tabular}

Committee of HGOPY. Each participant's written consent was obtained before the interview was conducted.

\section{Study participants and procedure}

A total of 97 cases were compared with 127 controls, making a case-control ration of $1: 1.3$. The study population was made up of teenagers aged between 12 and 19 years, contacted through phone calls, their phone numbers were retrieved from the medical records. The procedure consisted in booking home visits with all those who were reachable by telephone. An interview was then conducted and data collected on a pretested questionnaire. For those who were reachable by telephone but who were out of town, their interviews were done through phone calls. Adolescents whose parents or guardians did not consent to participate where excluded from the study.

\section{Data analysis and management}

Data was entered and analyzed using the Epi info 3.5.4 software. Tables were obtained with the help of Excel and Word 2013 software. The Chi square and Fischer's exact tests were used to compare variables. An error margin of $5 \%$ was set. The Odds ratio with $95 \%$ confidence interval was used to determine statistically significant risk factors. A multivariate analysis was done to check for confounders. 


\section{Journal of Gynecology and Women's Health}

\begin{tabular}{|c|c|c|c|c|}
\hline South-West & $0(0)$ & $1(0.8)$ & $0(0-24.88)$ & 0.570 \\
\hline \multicolumn{5}{|c|}{ Religion } \\
\hline Catholic & $56(57.7)$ & $76(59.8)$ & $0.92(0.53-1.57)$ & 0.430 \\
\hline Protestant & $29(29.9)$ & $37(29.1)$ & $1.04(0.58-1.85)$ & 0.510 \\
\hline Islam & $12(12.4)$ & $14(11)$ & $1.14(0.49-2.62)$ & 0.460 \\
\hline \multicolumn{5}{|c|}{ Level of Education } \\
\hline Primary & $3(3.1)$ & $3(2.4)$ & $1.32(0.22-7.82)$ & 0.520 \\
\hline Secondary & $81(83.5)$ & $104(81.9)$ & $1.12(0.55-2.29)$ & 0.450 \\
\hline Higher/University & $13(13.4)$ & $20(15.7)$ & $0.83(0.38-1.76)$ & 0.380 \\
\hline \multicolumn{5}{|c|}{ Residence/Distance from Hospital } \\
\hline $0 \mathrm{~km}$ & $16(16.5)$ & $23(18.1)$ & $0.89(0.44-1.8)$ & 0.450 \\
\hline $0-5 \mathrm{~km}$ & $49(50.5)$ & $63(49.6)$ & $1.04(0.61-1.76)$ & 0.500 \\
\hline $5-10 \mathrm{~km}$ & $27(27.8)$ & $36(28.3)$ & $0.98(0.54-1.76)$ & 0.530 \\
\hline $10-15 \mathrm{~km}$ & $11(11.3)$ & $9(7.1)$ & $1.68(0.65-4.36)$ & 0.190 \\
\hline$>15 \mathrm{~km}$ & $3(3.1)$ & $3(2.4)$ & $1.32(0.22-7.82)$ & 0.520 \\
\hline \multicolumn{5}{|c|}{ Civil Status } \\
\hline Married & $20(20.6)$ & $31(24.4)$ & $0.8(0.42-1.52)$ & 0.310 \\
\hline Spinster & $56(57.7)$ & $62(48.8)$ & $1.43(0.84-2.45)$ & 0.120 \\
\hline Cohabitation & $21(21.6)$ & $34(26.8)$ & $0.76(0.4-1.41)$ & 0.230 \\
\hline
\end{tabular}

We recorded a total of 524 pregnant adolescents who had West Region $(\mathrm{OR}=12.89, \mathrm{P}<0.001)$. Catholic Christians made started antenatal consultation at HGOPY. Two hundred and forty three were eligible, and among them, 19 did not give their consent. Hence, we enrolled 224 participants of whom 97 were cases of loss to follow-up and 127 were those who completed their antenatal visits and delivered in HGOPY (the control group). The 17-19 years age group was the most represented (86.6\%) with an average of $18 \pm 1.2$ years. Students constituted the majority, 59.1\%. Adolescents originating from the West region of the country were the most represented (38.1\%) followed by those from the Centre region (35.1\%). The risk of loss to up $57.7 \%$ of the study population. Secondary education was the most represented level of education (83.5\%), followed by higher education $(13.4 \%)$ and then primary education $(3.1 \%)$. Most of the adolescents lived within a radius of 5 kilometres from the hospital (50.5\%). Only $3.1 \%$ lived at $15 \mathrm{~km}$ and beyond from the hospital. However, the average geographical distance was $6.9 \pm 16.6 \mathrm{~km}$. Spinsters represented $57.7 \%$ in the two groups, followed by $21.6 \%$ who were co-habiting and only $20.6 \%$ were married. Table 1 summarises the sociodemographic characteristics of the study population.

follow-up was multiplied by 13 for adolescents from the North

\section{Determinants of loss of follow-up during adolescent pregnancies}

Table 2: Individual characteristics of adolescents.

\begin{tabular}{|c|c|c|c|c|}
\hline Variables & Case & Control & OR $(95 \% \mathrm{CI})$ & P-value \\
\hline & $\mathrm{n}=97$ & $\mathrm{n}=127$ & & \\
\hline & $\mathrm{n}(\%)$ & $\mathrm{n}(\%)$ & & \\
\hline \multicolumn{5}{|c|}{ Perception of the Value of Pregnancy } \\
\hline Very important & $89(91.8)$ & $127(100)$ & $0.00(0.00-0.43)$ & $<0.001$ \\
\hline Normal & $7(7.2)$ & $0(0)$ & & \\
\hline \multicolumn{5}{|c|}{ Perception of the Geographical Distance } \\
\hline Very near & $24(24.7)$ & $59(46.5)$ & $0.38(0.21-0.68)$ & $<0.001$ \\
\hline Near & $34(35.1)$ & $65(51.2)$ & $0.51(0.3-0.89)$ & 0.01 \\
\hline Far & $21(21.6)$ & $0(0)$ & & $<0.001$ \\
\hline Very far & $18(18.6)$ & $3(2.4)$ & $9.42(2.89-40.88)$ & $<0.001$ \\
\hline \multicolumn{5}{|c|}{ Perception of the Cost of Pregnancy Care } \\
\hline Affordable & $28(28.9)$ & $125(68.3)$ & $0.01(0-0.02)$ & $<0.001$ \\
\hline Expensive & $57(58.8)$ & $0(0)$ & & $<0.001$ \\
\hline Very expensive & $12(12.4)$ & $2(1.6)$ & $8.82(2.14-58.89)$ & $<0.001$ \\
\hline
\end{tabular}




\section{Journal of Gynecology and Women's Health}

\begin{tabular}{|c|c|c|c|c|}
\hline \multicolumn{5}{|c|}{ Perception of Delivery Fees } \\
\hline Affordable & $7(7.2)$ & $122(96.1)$ & $0(0-0.01)$ & $<0.001$ \\
\hline Expensive & $6(6.2)$ & $2(1.6)$ & $4.12(0.85-30.07)$ & 0.070 \\
\hline Very expensive & $20(20.6)$ & $2(1.6)$ & $16.23(4.2-104.3)$ & $<0.001$ \\
\hline No idea & $64(66)$ & $0(0)$ & & $<0.001$ \\
\hline \multicolumn{5}{|c|}{ Perception of the Reception by Hospital Staff } \\
\hline Friendly & $43(44.3)$ & $114(89.8)$ & $0.09(0.04-0.18)$ & $<0.001$ \\
\hline Agressive & $51(52.6)$ & $12(9.4)$ & $10.63(5.22-22.24)$ & $<0.001$ \\
\hline \multicolumn{5}{|c|}{ Media Exposure } \\
\hline Television & $97(100)$ & $126(99.2)$ & & 0.57 \\
\hline Radio & $9(9.3)$ & $9(7.1)$ & $0.90(0.35-2.21)$ & 0.500 \\
\hline Internet & $11(11.3)$ & $8(6.3)$ & $1.90(0.72-5.14)$ & 0.140 \\
\hline \multicolumn{5}{|c|}{ Age of Pregnancy at First ANC } \\
\hline First trimester & $32(33)$ & $46(36.2)$ & $0.87(0.49-1.52)$ & 0.360 \\
\hline Second trimester & $57(58.8)$ & $68(53.5)$ & $1.24(0.72-2.12)$ & 0.260 \\
\hline Third trimester & $8(8.2)$ & $13(10.2)$ & $0.79(0.3-1.99)$ & 0.400 \\
\hline \multicolumn{5}{|c|}{ Causes for Late Start of Consultations } \\
\hline Personal initiative & $7(7.2)$ & $18(14.2)$ & $0.47(0.18-1.16)$ & 0.080 \\
\hline Family member's initiative & $8(8.2)$ & $5(3.9)$ & $2.19(0.68-7.57)$ & 0.140 \\
\hline Geographical instability & $4(4.1)$ & $9(7.1)$ & $0.56(0.15-1.87)$ & 0.260 \\
\hline Fear of the Family & $16(16.5)$ & $13(10.2)$ & $1.73(0.78-3.87)$ & 0.120 \\
\hline ANC started elsewhere & $15(15.5)$ & $19(15)$ & $1.04(0.49-2.18)$ & 0.530 \\
\hline Ignorant of pregnancy & $8(8.2)$ & $7(5.5)$ & $1.54(0.52-4.61)$ & 0.290 \\
\hline Lack of financial means & $3(3.1)$ & $5(3.9)$ & $0.78(0.15-3.46)$ & 0.520 \\
\hline Ignorant of when to start & $4(4.1)$ & $4(3.1)$ & $1.32(0.29-6)$ & 0.480 \\
\hline
\end{tabular}

Table 3: Family characteristics of the adolescents.

\begin{tabular}{|c|c|c|c|c|}
\hline Variables & Case & Control & OR $(95 \% \mathrm{CI})$ & P-value \\
\hline & $\mathrm{n}=97$ & $\mathrm{n}=127$ & & \\
\hline & $\mathrm{n}(\%)$ & $\mathrm{n}(\%)$ & & \\
\hline \multicolumn{5}{|c|}{ Household Size } \\
\hline Small (2-3 persons) & $36(37.1)$ & $68(53.5)$ & $0.51(0.30-0.88)$ & 0.010 \\
\hline Average (4-6 persons) & $31(32)$ & $50(39.4)$ & $0.72(0.41-1.26)$ & 0.160 \\
\hline Large ( $\geq 6$ persons) & $30(30.9)$ & $9(7.1)$ & $5.87(2.66-13.67)$ & $<0.001$ \\
\hline \multicolumn{5}{|c|}{ Living Standard of Household } \\
\hline Poor (Monthly income of adolescent< 28,500 FCFA) & $68(70.1)$ & $63(49.6)$ & $2.38(1.36-4.18)$ & $<0.001$ \\
\hline Not poor (Monthly income of adolescent $>28,500$ FCFA) & $29(29.9)$ & $64(50.4)$ & $0.42(0.24-0.73)$ & - \\
\hline \multicolumn{5}{|c|}{ Relation with Head of the Household } \\
\hline Daughter/sister & $43(44.3)$ & $48(37.8)$ & $1.31(0.76-2.25)$ & 0.200 \\
\hline Spouse & $19(19.6)$ & $31(24.4)$ & $0.75(0.39-1.44)$ & 0.240 \\
\hline Concubine & $19(19.6)$ & $23(18.1)$ & $1.1(0.55-2.17)$ & 0.460 \\
\hline Far relation & $16(16.5)$ & $25(19.7)$ & $0.81(0.4-1.61)$ & 0.330 \\
\hline \multicolumn{5}{|c|}{ Gender of Head of Household } \\
\hline Male & $79(81.4)$ & $105(82.7)$ & $0.92(0.46-1.85)$ & - \\
\hline Female & 18 (18.6) & $22(17.3)$ & $1.09(0.54-2.17)$ & 0.470 \\
\hline \multicolumn{5}{|c|}{ Educational Level of Head of Household } \\
\hline Primary & $13(13.4)$ & $21(16.5)$ & $0.78(0.36-1.65)$ & 0.320 \\
\hline Secondary & $60(61.9)$ & $69(54.3)$ & $1.36(0.79-2.34)$ & 0.160 \\
\hline
\end{tabular}


Journal of Gynecology and Women's Health

\begin{tabular}{|c|c|c|c|c|}
\hline Higher Education & $24(24.7)$ & $36(28.3)$ & $0.83(0.45-1.52)$ & 0.330 \\
\hline \multicolumn{5}{|c|}{ Occupation of Head Of Household } \\
\hline Student & $2(2.1)$ & $0(0)$ & - & 0.190 \\
\hline Housewife & $0(0)$ & $2(1.6)$ & $0(0-4.54)$ & 0.320 \\
\hline Jobless & $0(0)$ & $1(0.8)$ & $0(0-24.88)$ & 0.570 \\
\hline Informal sector & $54(55.7)$ & $60(47.2)$ & $1.4(0.82-2.39)$ & 0.130 \\
\hline Privauté sector & $25(25.8)$ & $29(22.8)$ & $1.17(0.63-2.18)$ & 0.360 \\
\hline Civil servant & $16(16.5)$ & $35(27.6)$ & $0.52(0.26-1)$ & 0.040 \\
\hline \multicolumn{5}{|c|}{ Person Having Oriented the Adolescent to ANC } \\
\hline Family member & $66(68.0)$ & $81(63.8)$ & $1.21(0.69-2.13)$ & 0.300 \\
\hline Concubine & $2(2.1)$ & $0(0.0)$ & - & 0.190 \\
\hline Referred & $3(3.1)$ & $2(1.6)$ & $1.99(0.29-17)$ & 0.370 \\
\hline Personal initiative & $5(5.2)$ & $15(11.8)$ & $0.41(0.13-1.13)$ & 0.070 \\
\hline Advice from a friend & $5(5.2)$ & $15(11.8)$ & $0.41(0.13-1.13)$ & 0.070 \\
\hline \multicolumn{5}{|c|}{ Person Having Accompanied the Adolescent to the First ANC } \\
\hline Family member & $58(59.8)$ & $73(57.5)$ & $1.1(0.64-1.89)$ & 0.420 \\
\hline Concubine and family & $6(6.2)$ & $3(2.4)$ & $2.73(0.66-13.59)$ & 0.140 \\
\hline Friend & $0(0)$ & $2(1.6)$ & $0(0-4.54)$ & 0.320 \\
\hline Nobody & $21(21.6)$ & $33(26)$ & $0.79(0.42-1.47)$ & 0.280 \\
\hline Boy friend & $10(10.3)$ & $6(4.7)$ & $2.32(0.81-7.09)$ & 0.090 \\
\hline \multicolumn{5}{|c|}{ Person Having Paid Medical Fees of Pregnancy } \\
\hline Head of family & $76(78.4)$ & 49 (38.6) & $5.76(3.16-10.59)$ & $<0.001$ \\
\hline Another family member & $5(5.2)$ & $38(29.9)$ & $0.13(0.04-0.32)$ & $<0.001$ \\
\hline Boy friend & $5(5.2)$ & $29(22.8)$ & $0.18(0.06-0.47)$ & $<0.001$ \\
\hline Herself & $4(4.1)$ & $6(4.7)$ & $0.87(0.21-3.26)$ & 0.550 \\
\hline
\end{tabular}

The majority (91.8\%) of adolescents perceived pregnancy as an important state that needed medical attention. The long wait during antenatal consultation as observed by $71.1 \%$ of the adolescents, multiplied by 5.77 times the risk of loss to followup $(\mathrm{P}<0.001)$. Those who considered their residence as far from the hospital, were at 9.4 times risk of interrupting antenatal visits $(\mathrm{P}<0.001)$. Medical cost of follow-up when considered to be expensive, multiplied by 8.8 times the risk of interrupting discontinuing antenatal visits $(\mathrm{P}<0.001)$. Those who saw delivery fees to be expensive had a 16.2 times risk of not ending up her pregnancy in HGOPY $(\mathrm{P}<0.001)$. The risk of discontinuing care was multiplied by 10.6 times when the health personnel presented an aggressive attitude $(\mathrm{P}<0.001)$. More than half of the adolescents (58.8\%) started antenatal consultations in the second trimester (Table 2). In $16.5 \%$ of the cases, the fear of disclosing the pregnancy to the family caused the delay. In $15.5 \%$ of the cases, the visits were started in a health centre Table 4: Table illustrating past medical history of adolescents.

\begin{tabular}{|c|c|c|c|c|}
\hline Variables & Case & Control & OR (95\% CI) & P-value \\
\hline & $\mathrm{n}=97$ & $\mathrm{n}=127$ & $\mathrm{n}$ \\
\hline & $\mathrm{n}(\%)$ & $\mathrm{n}(\%)$ & 0.002 \\
\hline Yes & $26(26.8)$ & $14(11.0)$ & $0.60(0.37-0.88)$ & \\
\hline No & $71(73.2)$ & $113(89.0)$ & $0.34(0.16-0.69)$ & \\
\hline
\end{tabular}

before transferring to HGOPY. A good proportion (46.6\%) did all their consultations in HGOPY but delivered in a different centre. After the first consultation, $20.6 \%$ discontinued consultations in HGOPY, meanwhile $14.4 \%$ stopped after the second consultation. Adolescents from large family sizes represented $30.9 \%$ and in $70.1 \%$ of them, their families were poor, with a 2.38 risk of discontinuing care $(\mathrm{P}<0.001)$. The average monthly family revenue was 35133.9 FCFA. In $81.4 \%$ of the cases, the head of the family was a male and in $61.9 \%$ of cases, the family head's level of education was secondary and $55.7 \%$ of them worked in the informal sector. In $78.4 \%$ of the cases, the medical fees were paid by the head of the family and this increased by 5.76 times the risk of discontinuing medical consultations in HGOPY (Table 3). Sociocultural considerations affected follow-up in $7.2 \%$ of adolescents, due to the fact that a first baby born in the home of the man in $57.1 \%$ of cases and in the home of the woman in $42.9 \%$ of the cases. 


\section{Journal of Gynecology and Women's Health}

\begin{tabular}{|c|c|c|c|c|}
\hline \multicolumn{5}{|c|}{ Type of Medical History } \\
\hline Ophtalmological & $4(4.1)$ & $1(0.8)$ & $5.42(0.66-135.06)$ & 0.110 \\
\hline Gynecological & $5(5.2)$ & $2(1.6)$ & $3.4(0.65-25.62)$ & 0.130 \\
\hline Digestive & $5(5.2)$ & $4(3.1)$ & $1.67(0.41-7.15)$ & 0.340 \\
\hline Neurological & $4(4.1)$ & $0.0(0)$ & - & 0.030 \\
\hline Hematological & $3(3.1)$ & $0(0)$ & - & 0.080 \\
\hline Respiratory & $3(3.1)$ & $2(1.6)$ & $1.99(0.29-17)$ & 0.370 \\
\hline Cardiac & $2(2.1)$ & $3(2.4)$ & $0.87(0.1-5.96)$ & 0.630 \\
\hline Dental & $0(0)$ & $2(1.6)$ & $0(0-4.54)$ & 0.320 \\
\hline \multicolumn{5}{|c|}{ Follow-Up of Medical Condition } \\
\hline Yes & $18(18.6)$ & $11(8.7)$ & $1.39(0.48-4.06)$ & \\
\hline No & $8(8.3)$ & $3(2.4)$ & $1.63(0.35-7.48)$ & 0.404 \\
\hline \multicolumn{5}{|c|}{ Venue of Follow-Up of Medical Condition } \\
\hline HGOPY & $13(13.4)$ & $9(7.1)$ & $1.43(0.40-5.12)$ & \\
\hline Out of HGOPY & $5(5.2)$ & $2(1.6)$ & $1.73(0.27-10.97)$ & 0.453 \\
\hline
\end{tabular}

After logistic regression, statistically significant risk factors for loss to follow-up were: origin from the North West Region, working in the informal sector, the aggressive attitude

Table 5: Table illustrating the gynecologic past history of adolescents.

\begin{tabular}{|c|c|c|c|c|}
\hline Variables & Case & Control & OR $(95 \% \mathrm{CI})$ & P-value \\
\hline & $\mathrm{n}=97$ & $\mathrm{n}=127$ & & \\
\hline & $\mathrm{n}(\%)$ & $\mathrm{n}(\%)$ & & \\
\hline \multicolumn{5}{|c|}{ Gravidity } \\
\hline Primigravida & $79(81.4)$ & $102(80.3)$ & $0.97(0.73-1.28)$ & 0.490 \\
\hline Multigravida & $18(18.6)$ & 25 (19.7) & $0.93(0.47-1.83)$ & \\
\hline \multicolumn{5}{|c|}{ Parity } \\
\hline Primiparous & $88(90.7)$ & $110(86.6)$ & $0.90(0.63-1.15)$ & 0.458 \\
\hline Pauciparous & $9(9.3)$ & $17(13.4)$ & $0.66(0.28-1.56)$ & \\
\hline \multicolumn{5}{|c|}{ Number of Surgical Interventions on the Uterus } \\
\hline 1 & $13(13.4)$ & $27(21.3)$ & $0.57(0.27-1.18)$ & 0.090 \\
\hline 2 & $2(2.1)$ & $0(0)$ & - & \\
\hline \multicolumn{5}{|c|}{ Type of Surgical Operation on the Uterus } \\
\hline Curetage & $5(5.2)$ & $4(3.1)$ & $1.67(0.41-7.15)$ & 0.340 \\
\hline Caesarean section & $10(10.3)$ & $23(18.1)$ & $0.52(0.23-1.14)$ & \\
\hline \multicolumn{5}{|c|}{ Indication of Caesarean Section } \\
\hline Breech presentation & $1(1)$ & $4(3.1)$ & $0.32(0.01-2.61)$ & 0.280 \\
\hline Foetal macrosomia & $2(2.1)$ & $3(2.4)$ & $0.87(0.1-5.96)$ & 0.630 \\
\hline Preeclampsia & $1(1)$ & $5(3.9)$ & $0.25(0.01-1.88)$ & 0.180 \\
\hline Dystocic pelvis & $3(3.1)$ & $6(4.7)$ & $0.64(0.13-2.66)$ & 0.40 \\
\hline Fœtal umbilical cord presentation & $0(0)$ & $2(1.6)$ & $0(0-4.54)$ & 0.320 \\
\hline Acute fœtal distress & $0(0)$ & $2(1.6)$ & $0(0-4.54)$ & 0.320 \\
\hline Third trimester genitalinfection & $0(0)$ & $1(0.8)$ & $0(0-24.88)$ & 0.570 \\
\hline \multicolumn{5}{|c|}{ Indication for Curetage } \\
\hline Incomplete spontaneous abortion & $3(3.1)$ & $2(1.6)$ & $1.99(0.29-17)$ & 0.370 \\
\hline Incomplete induced abortion & $2(2.1)$ & $2(1.6)$ & $1.32(0.13-12.81)$ & 0.580 \\
\hline \multicolumn{5}{|c|}{ Fœtal Complications in Previous Pregnancies } \\
\hline Tight nuchal cord & $1(1)$ & $0(0)$ & - & 0.430 \\
\hline
\end{tabular}

of the health personnel, delivery fees considered as expensive, belonging to a large family size and when the medical fees were paid solely by the head of the family (Table 4-6). 


\section{Journal of Gynecology and Women's Health}

\begin{tabular}{|c|c|c|c|c|}
\hline Small birth weight & $0(0)$ & $1(0.8)$ & - \\
\hline \multicolumn{5}{|c|}{ Maternal Complications in Previous Pregnancies } \\
\hline PPH due to retained products & $2(2.1)$ & $0(0)$ & - & - \\
\hline Diabetes in pregnancy & $0(0)$ & $1(0.8)$ & - & \\
\hline
\end{tabular}

Table 6: Logistic regression following multivariate analysis.

\begin{tabular}{|c|c|c|}
\hline Variables & Adjusted OR (95\% CI) & P-value \\
\hline North West Region of origin & $82.91(3.59-1912.07)$ & 0.006 \\
\hline Occupation in the informal sector & $19.34(2.91-128.61)$ & 0.002 \\
\hline Long wait at ANC & $6.90(2.03-23.44)$ & 0.002 \\
\hline The perception of geographical distance as being very far & $5.63(0.68-46.88)$ & 0.110 \\
\hline The perception of cost of care of pregnancy as being very expensive & $0.56(0.05-5.75)$ & 0.623 \\
\hline The perception of delivery fees as being very expensive & $202.44(13.63-3007.85)$ & $<0.001$ \\
\hline Agressive attitude at reception by hospital staff & $9.04(2.52-32.39)$ & 0.001 \\
\hline Belonging to a large family size & $16.54(3.10-88.15)$ & 0.001 \\
\hline Poor standard of living of the family & $2.0(0.65-6.20)$ & 0.226 \\
\hline Fees for pregnancy care by the head of the family & $23.06(5.66-94.01)$ & $<0.001$ \\
\hline
\end{tabular}

\section{Discussion}

The aim of this research work was to identify the risk factors associated with loss to follow-up of adolescent pregnancies at the Yaounde Gynaeco-Obstetric and Paediatric Hospital. It was noticed that their socio-demographic characteristics, individual factors, family factors and cultural factors influenced the discontinuity of care in this hospital. The weak economic power, especially of those adolescents working in the informal sector like subsistent farming had an impact on the continuity of care in HGOPY. Rwenge JR and Tchamgoue HB had a similar finding in Cameroon in 2004 [4].

The region of origin of the adolescent was a significant factor associated with this loss to follow-up for teenagers originating from the North West region. This risk was multiplied by 13 , similar to that obtained by Rwenge JR et al. [4]. This could be explained by the culture of this region, wherein it is habitual that a woman's first delivery should take place either in the environment of her parents or in that of the husband's parents. Hence, teenage primarous descendants of the North West region may have travelled back to their home towns to deliver leading to loss of follow up in the study setting.

The geographical distance from their residence to the hospital was a big limiting factor. Those who considered the distance as far, had a 9.42 risk of interrupting follow-up at HGOPY. Tollegbe A in 2004 in Bénin and Kamga G-R in 2010 in the North of Cameroon found these risks multiplied respectively by 5 and 4 [5-7]. This difference could be explained by the fact that in their series, adolescents from rural areas residing at more than 15 kilometres from the hospitals were those greatly affected. In our series, this aspect concerned both those living in and out of the town of Yaounde. Our adolescents had a more subjective perception of this notion of far distance, which in some cases the distance was not really far.
The cost of care of pregnancy and delivery fees considered as expensive were significant factors associated with loss to followup. This finding correlates with the declaration by the French Red Cross in Mali in 2013 stating that financial accessibility is the main barrier to health care in health facilities. The bulk of this high cost was mostly the paraclinical investigations in the first visit that ranged from a hundred to a hundred and twenty thousand francs. The required delivery caution fees of 50,000 FCFA was considered expensive and not easy to gather and deposit in a single instalment.

The aggressive attitude of the hospital staff at the reception, Radiology service, and at the outpatient consultation boxes of gynaecology increased the risk of discontinuing follow-up by 7.4 times. A Prual in 1999 got a similar result in West Africa [8]. The aggressiveness mostly was because the nurses were judgemental on them getting pregnant at a tender age and their impolite language. This attitude however goes against the WHO 1998 declaration on the impartial nature of care to women seeking the services of reproductive health.

The long waiting time at the reception to get a medical file (30 minutes) and infront of the consultation boxes ( 4 hours), multiplied the risk of discontinuing follow-up by 5.77 times. Some of these adolescents would return without being consulted. Most of the adolescents being students (59.8\%), were therefore greatly affected because they had to miss classes on such days in order to be consulted. The phenomenon was further aggravated by the fact that some of these adolescents arrived the hospital as early as 6:00 am in order to be consulted early, so as to arrive in school early for classes. That was unfortunately very often not the case.

Some of the difficulties encountered by these adolescents were the delay in rendering results of diagnostic tests. Some had their results even missing, and also the inability of being 
consulted if the medical file could not be retrieved from the archival service. Adolescents from large family sizes were more at risk of discontinuing care. The risk was multiplied by 5.87 times. This result was similar with that of Rwenge JR and Tchamgoue HB in Cameroon in 2004 [4]. This could be explained by the fact that large family sizes have a much weaker economic power and as such the financial access for medical care cannot easily be guaranteed [9].

The living standards of their families also significantly affected their adherence to follow-up in this hospital. Those from poor families were 2.38 times at risk of discontinuing care. This finding was similar to that of Rwenge JR and Tchamgoue HB in Cameroon in 2004 [4]. This was simply due to the fact that $69.1 \%$ of these adolescents came from families with low standard of living and this impacts their health care because health financing in Cameroon is mostly taken care of by direct payment from the family financial basket if at all there exists one [5].

Whenever the medical fees of the pregnancy was paid by her family head, the risk of discontinuing care was multiplied by 5.76. This could be explained simply by the large family sizes and their weak economic power. Cultural barriers were significant in interrupting follow-up at HGOPY. This was particularly true for those adolescents from the West, North and Extreme North Regions where their first deliveries must take place in the homes of either the adolescent's parents or in the home of the partner's parents. Tollegbe A in Benin in 2004 obtained a similar result [5].

\section{Conclusion}

The rate of loss to follow up for antenatal visits in adolescents is high. Multiple cultural, sociodemographic, logistics and medical factors contribute to increase this significantly. Improving the attitude of the hospital staff at reception, reducing the waiting time and the cost of pregnancy care and delivery fees for adolescents would significantly reduce the rate of loss to follow-up and as such, improve upon the reproductive health of the adolescent population.

\section{Conflict of Interest}

The authors declare no conflict of interest. This research project did not benefit from any research grant from any funding agency.

\section{References}

1. World Health Organization (2016) Adolescents: health risks and solutions.

2. Djoumetio S (2010) Pauvreté et grossesse des adolescentes au Cameroun [mémoire professionnel d'ingénieur d'Application de la Statistique]. Yaoundé: Institut Sous-Régional de Statistique et d'Economie Appliquée, p. 91.

3. Tebeu PM, Kemfang JD, Sandjong DI, Kongnyuy E, Halle G, et al. (2010) Geographic Distribution of Childbirth among Adolescents in Cameroon from 2003 to 2005. Obstet Gynecol int 80(5): 81-88.

4. Rwenge JR, Tchamgoue HB (2011) Facteurs sociaux de l'utilisation des services de soins obstetricaux parmi les adolescentes camerounaises. Afr J Reprod Health 15(3): 81-92.

5. Tollegbe A (2004) Les facteurs explicatifs de la discontinuité des soins obstétricaux en Afrique: cas du Bénin [mémoire professionnel d'études supérieures spécialisées en démographie]. Yaoundé: Institut de formation et de recherche démographiques. Institut, p. 61.

6. Croix-Rouge Française (2013) Déterminants socio-culturels de l'accès et l'utilisation des services de santé maternelle et néonatale au Mali : Cas de la Commune I du district de Bamako. Mali, p. 55.

7. Kamga GR (2010) Déterminants Socio-Economiques du Choix du Lieu d'Accouchement des Femmes dans le District de Santé de Lagdo, Nord Cameroun [mémoire Pour l'obtention du Diplôme Inter-Universitaire de l'Université de Cocody Abidjan]. Abidjan: Université de Cocody, p. 25.

8. Prual A (1999) Grossesse et accouchement en Afrique de l'Ouest: vers une maternité à moindre risque? Santé Publique. 11(2): 167-191.

9. Haque N (2009) Individual's characteristics affecting Maternal Health Services utilization: Married adolescents and their use of Maternal Health Services in Bangladesh. The Internet Health J 22(2): 171-180.

\begin{tabular}{|l|}
\hline \multicolumn{1}{|c|}{ Your next submission with Juniper Publishers } \\
will reach you the below assets \\
- Quality Editorial service \\
- Swift Peer Review \\
- Reprints availability \\
- E-prints Service \\
- Manuscript Podcast for convenient understanding \\
- Global attainment for your research \\
- Manuscript accessibility in different formats \\
( Pdf, E-pub, Full Text, Audio) \\
- Unceasing customer service \\
Track the below URL for one-step submission \\
https://juniperpublishers.com/online-submission.php \\
\hline
\end{tabular}

